\title{
Low roll-off of efficiency at high current density in phosphorescent organic light emitting diodes
}

\author{
Jae-Wook Kang, ${ }^{\text {a) }}$ Se-Hyung Lee, Hyung-Dol Park, Won-lk Jeong, Kyung-Mo Yoo, \\ Young-Seo Park, and Jang-Joo Kim ${ }^{\text {b) }}$ \\ Department of Materials Science and Engineering, Seoul National University, Seoul 151-744, Korea \\ and Center for Organic Light Emitting Diode (COLED), Seoul National University, Seoul 151-744, Korea
}

(Received 28 March 2007; accepted 9 May 2007; published online 31 May 2007)

\begin{abstract}
The authors demonstrate that the reduction of quantum efficiency with increasing current density in phosphorescent light emitting diodes (PhOLEDs) is related to the formation of excitons in hole transporting layer based on the analysis of emission spectra and exciton formation zone. Low roll-off of efficiency in a PhOLED was achieved using dual emitting layers (D-EMLs) by confining the exciton formation near the interface between the emitting layers. The external quantum efficiency was maintained almost constant up to $22 \mathrm{~mA} / \mathrm{cm}^{2}\left(10000 \mathrm{~cd} / \mathrm{m}^{2}\right)$ by adopting the D-EMLs in $\operatorname{Ir}(\mathrm{ppy})_{3}$ based PhOLEDs, resulting in high external quantum efficiency ( $\eta_{\text {ext }}$ $=13.1 \%$ ) at high luminance. (C) 2007 American Institute of Physics. [DOI: 10.1063/1.2745224]
\end{abstract}

Phosphorescent organic lighting emitting diodes (PhOLEDs) have received considerable attention due to their ability of highly efficient emission compared with fluorescent OLEDs. ${ }^{1-4}$ Through harvesting of both singlet and triplet excitons, the external quantum efficiency $\left(\eta_{\text {ext }}\right)$ of PhOLEDs has reached above $20 \%$ by using the optimized material systems, ${ }^{5-7} p-i-n$ structures, ${ }^{8,9}$ and microcavity structures. ${ }^{10,11}$ However, the efficiency roll-off (the decrease of efficiency with increasing current density) occurs at much lower luminance than required in displays or solid-state lighting. The roll-off of the quantum efficiency is one of the most significant problems facing electrophosphorescent devices and its origin was attributed to the triplet-triplet annihilation coming from long lifetime of triplet excitons, ${ }^{12,13}$ electric field induced dissociation of excitons, ${ }^{14}$ and tripletpolaron annihilation. $^{12,13}$

In this letter, we report that the roll-off of the quantum efficiency with an increasing current density is related to the exciton formation in the hole transporting layer (HTL). Analysis of the steady state emission spectra indicated that the significant portion of the efficiency reduction is originated from the more and more exciton formation in the HTL with increasing current density. Based on the results, we fabricated devices with double emitting layers (D-EMLs) in order to confine the exciton formation in the emitting layers. The external quantum efficiency $\left(\eta_{\text {ext }}\right)$ was maintained constant up to $22 \mathrm{~mA} / \mathrm{cm}^{2}\left(10000 \mathrm{~cd} / \mathrm{m}^{2}\right)$ by adopting the D-EMLs in $\operatorname{Ir}(\text { ppy })_{3}$ based PhOLEDs, resulting in high external quantum efficiency at high luminescence compared to the devices with single emitting layer (S-EML). The OLEDs with D-EMLs show significantly lower roll-off of efficiency $\left[\eta_{\text {ext }}=13.1 \%\right.$ at $\left.10000 \mathrm{~cd} / \mathrm{m}^{2}\left(22 \mathrm{~mA} / \mathrm{cm}^{2}\right)\right]$ than conventional S-EML OLEDs $\left[\eta_{\mathrm{ext}}=7.8 \%\right.$ at $5400 \mathrm{~cd} / \mathrm{m}^{2}$ $\left(20 \mathrm{~mA} / \mathrm{cm}^{2}\right)$, and $6.9 \%$ at $\left.10000 \mathrm{~cd} / \mathrm{m}^{2}\left(40 \mathrm{~mA} / \mathrm{cm}^{2}\right)\right]$.

The OLEDs were fabricated by thermal evaporation onto a cleaned glass substrate precoated with indium tin oxide

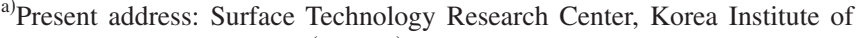
Machinery and Materials (KIMM), Changwon 641-010, Korea.

${ }^{b}$ Author to whom correspondence should be addressed; electronic mail: jjkim@snu.ac.kr
}

(ITO) without breaking the vacuum. Prior to organic layer deposition, ITO substrates were exposed to UV-ozone flux for $10 \mathrm{~min}$ following degreasing in aceton and isoprophyl alcohol. All organic layers were grown by thermal evaporation at the base pressure of $<5 \times 10^{-8}$ Torr in the following order: HTL/EML/hole blocking layer (HBL)/ electron transporting layer (ETL)/cathode. 40-nm-thick $4^{\prime}$-bis $[N$-(1-naphthyl)- $N$-phenyl-amino]biphenyl (NPB) was used as the HTL, 30-nm-thick $N, N^{\prime}$-dicarbazolyl4-4'-biphenyl (CBP) doped with 6 wt \% $\operatorname{Ir}(\mathrm{ppy})_{3}$ as the S-EML, 10-nm-thick 2,9-dimethyl-4,7-diphenyl-1.10phenanthroline (BCP) as the HBL, and 40-nm-thick tris-(8-hydroxyquinoline) aluminum as the ETL, respectively. For the device with D-EMLs, 20-nm-thick $4,4^{\prime}, 4^{\prime \prime}$-tris $(N$-carbazolyl)-triphenylamine (TCTA) and 10 -nm-thick CBP doped with 6 wt \% $\operatorname{Ir}(\mathrm{ppy})_{3}$, respectively, were used as the emitting layer. Finally, the cathode consisting of a 1-nm-thick LiF and a 100-nm-thick layer of Al was deposited onto the sample surface. Figure 1 shows the structure of the devices and the materials used in this study. Current density-voltage-luminescence $(J-V-L)$ characteristics of the OLEDs were measured simultaneously using a Keithley 2400 programable source meter and SpectraScan PR650 (Photo Research).

Current density-voltage-luminance $(J-V-L)$ characteristics of the phosphorescent OLEDs are shown in Fig. 2(a). The device with D-EMLs shows a lower driving voltage than S-EML. The driving voltage at $1000 \mathrm{~cd} / \mathrm{m}^{2}$ was 5.4 and 7.3 V for D-EML and S-EML devices, respectively. Quantum efficiency and power efficiency of the devices are displayed in Fig. 2(b). Initial quantum efficiency is almost the same between the S-EML and the D-EML devices. However, the roll-off of the quantum efficiency in the D-EML device is much smaller than the S-EML device. The quantum efficiency of the D-EML device was maintained almost the same with $13 \%-14 \%$ up to $10000 \mathrm{~cd} / \mathrm{m}^{2} \quad\left[\eta_{\text {ext }}=13.5 \%\right.$ at $10 \mathrm{~cd} / \mathrm{m}^{2} \quad\left(0.02 \mathrm{~mA} / \mathrm{cm}^{2}\right), \quad 14.0 \%$ at $\quad 100 \mathrm{~cd} / \mathrm{m}^{2}$ $\left(0.2 \mathrm{~mA} / \mathrm{cm}^{2}\right)$, and $13.1 \%$ at $\left.10000 \mathrm{~cd} / \mathrm{m}^{2}\left(22 \mathrm{~mA} / \mathrm{cm}^{2}\right)\right]$. In contrast, the SEML device exhibited significant reduction of efficiency $\left[\eta_{\mathrm{ext}}=14.4 \%\right.$ at $10 \mathrm{~cd} / \mathrm{m}^{2}\left(0.02 \mathrm{~mA} / \mathrm{cm}^{2}\right)$, $12.5 \%$ at $100 \mathrm{~cd} / \mathrm{m}^{2}\left(0.23 \mathrm{~mA} / \mathrm{cm}^{2}\right), 7.8 \%$ at $5400 \mathrm{~cd} / \mathrm{m}^{2}$ 


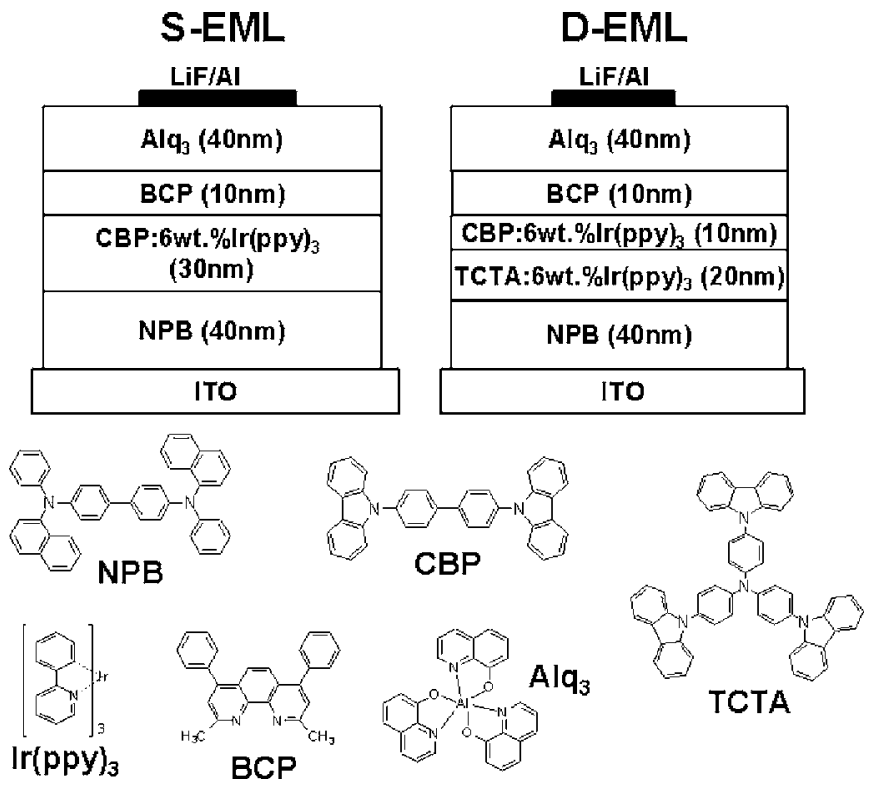

FIG. 1. Structure of electrophosphorescent devices with single and double emitting layers and the chemical structure of the materials used in the devices.

$\left(20 \mathrm{~mA} / \mathrm{cm}^{2}\right)$, and $6.9 \%$ at $\left.10000 \mathrm{~cd} / \mathrm{m}^{2}\left(40 \mathrm{~mA} / \mathrm{cm}^{2}\right)\right]$. Furthermore, the critical current densities $\left(J_{\text {cr }}\right)$, where the efficiency drops to half of this initial value as introduced by Baldo et al., ${ }^{12}$ are 30 and $560 \mathrm{~mA} / \mathrm{cm}^{2}$ for S-EML and D-EML devices, respectively. The $J_{\text {cr }}$ of D-EML device was much higher than the literature results by $\mathrm{He}$ et al. ${ }^{15}$ $\left(\sim 70 \mathrm{~mA} / \mathrm{cm}^{2}\right)$ and Adachi et al. ${ }^{16}\left(\sim 150 \mathrm{~mA} / \mathrm{cm}^{2}\right)$, resulting in a low roll-off of quantum efficiency at high current density.

Normalized electroluminance (EL) spectra of the devices at different current densities are shown in Fig. 3 in logarithmic scale in intensity. It is noteworthy that the emission around $440 \mathrm{~nm}$ grows with increasing current density in S-EML, and the emission begins to appear at the current density of $0.1 \mathrm{~mA} / \mathrm{cm}^{2}$, where the efficiency begins to be reduced. Since the emission is consistent with the emission from NPB, the roll-off of the quantum efficiency with increasing current density in the S-EML device seems to be related to the exciton formation in the NPB, the HTL. On the contrary, however, the D-EMLs device shows no emission of NPB layer up to $10 \mathrm{~mA} / \mathrm{cm}^{2}$, resulting in the high quantum efficiency at high luminance, showing negligible efficiency reduction with increasing current density up to $10000 \mathrm{~cd} / \mathrm{m}^{2}$. Above the current density of $10 \mathrm{~mA} / \mathrm{cm}^{2}$, the emission from NPB layer along with the triplet-triplet and triplet-polaron annihilations ${ }^{12,13}$ is responsible for the lowering of quantum efficiency.

These results imply that the recombination zone extends to HTL with increasing current and the degree of the extension is much larger in the S-EML device than D-EML. This can be understood based on the study of the location of the emission zones with increasing current density. To probe the exciton distribution in the devices, a 1-nm-thick 4-(dicyanomethylene)-2-(t-butyl)6-methyl-4Hpyran (DCJTB) was inserted as the sensing layer ${ }^{14}$ at the various positions in the EML and HTL, as shown in Fig. 4(c). DCJTB was chosen as the sensing layer because it emits a red color around $630 \mathrm{~nm}$ which is easily distinguishable from the CBP: $\operatorname{Ir}(\mathrm{ppy})_{3}$ emission. Even though the in-

Downloaded 18 Jul 2007 to 147.46.199.71. Redistribution subject
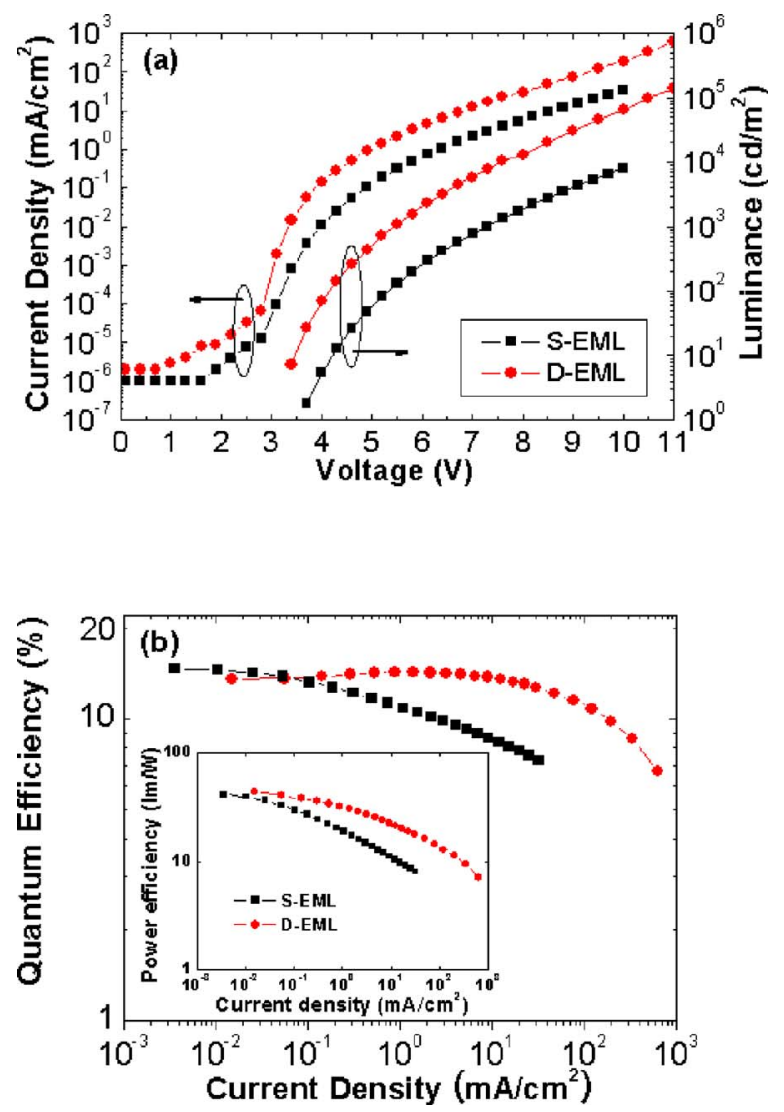

FIG. 2. (Color online) (a) Current density-voltage $(J-V)$ and luminescencevoltage $(L-V)$ characteristics, and (b) the external quantum efficiency and power efficiency of OLEDs for S-EML and D-EML.

sertion of the layer perturbs the charge transport in the devices, still we expect that the resulting emission spectra provide the qualitative picture of the variation of the exciton distribution with increasing current density.

Figure 4 shows a series of EL emission spectra at two different current densities at various positions of DCJTB layer for the S-EML and D-EMLs based devices. At low
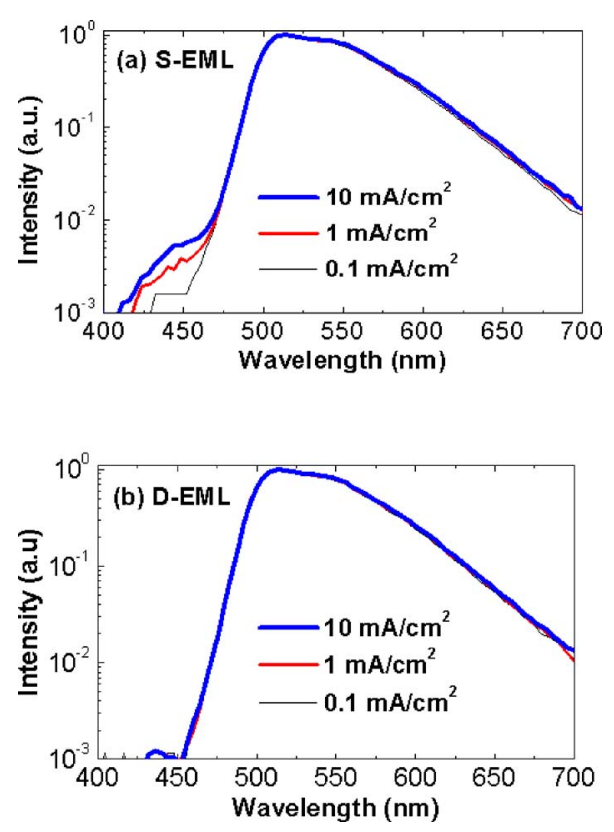

FIG. 3. (Color online) Normalized electroluminescent spectra of (a) S-EML and (b) D-EML as a function of current density.

AIP license or copyright, see http://apl.aip.org/apl/copyright.jsp 


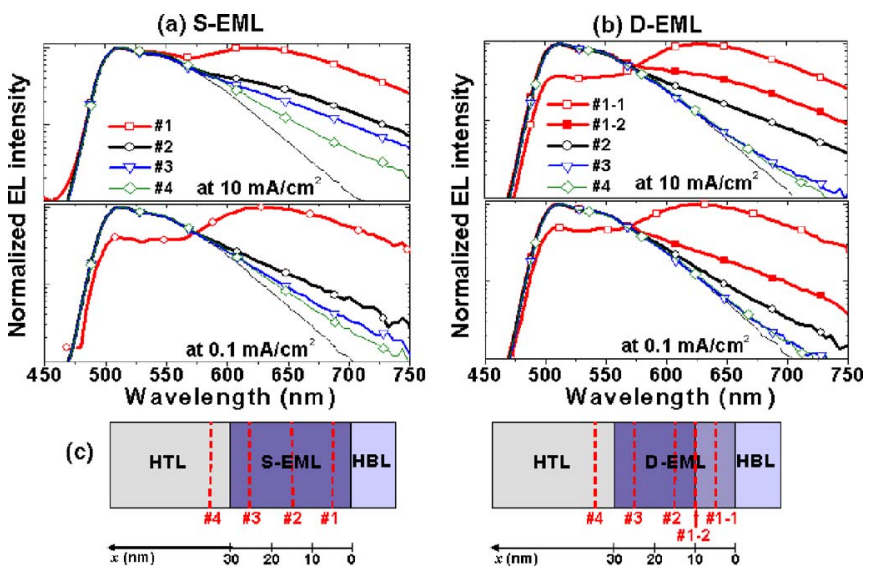

FIG. 4. (Color online) Normalized electroluminescent spectra of (a) S-EML and (b) D-EML having 1-nm-thick DCJTB exciton sensing layer at (c) various positions in the devices. The spectra were taken at different current densities. The solid line is the emission spectrum without DCJTB layer.

current density $\left(0.1 \mathrm{~mA} / \mathrm{cm}^{2}\right)$, the red emission close to HBL (position 1) was dominant and there was a little and negligible emission at positions 3 and 4 for the S-EML and D-EML devices, respectively, indicating that the recombination zone is close to HBL for both devices. At high current density $\left(10 \mathrm{~mA} / \mathrm{cm}^{2}\right)$, however, the S-EML device showed significant red emission close to and inside HTL (positions 3 and 4), demonstrating that the recombination zone penetrates the HTL. The portion of exciton formation near the hole blocking $\mathrm{BCP}$ layer is reduced at the high current density as indicated by the relative emission intensity ratio of $\operatorname{Ir}(\mathrm{ppy})_{3}$ and DCJTB at position 1. The device with D-EMLs, in contrast, shows most of the emission in the CBP: $\operatorname{Ir}(\mathrm{ppy})_{3}$ (positions 1-1 and 1-2), and in the TCTA: $\operatorname{Ir}(\mathrm{ppy})_{3}$ near the interface between the TCTA and CBP layers (position 2) at the current density of $10 \mathrm{~mA} / \mathrm{cm}^{2}$. Negligible emission at the positions 3 and 4 was observed even at the high current density. These results indicate the confinement of excitons inside of CBP: $\operatorname{Ir}(\mathrm{ppy})_{3}$ and TCTA: $\operatorname{Ir}(\mathrm{ppy})_{3}$ layers without the exciton formation close to HTL. More excitons are formed in TCTA: $\operatorname{Ir}(\mathrm{ppy})_{3}$ layer with increasing current, but little excitons are formed near or inside of the HTL. Analysis of the emission spectra confirms that the significant portion of the efficiency reduction of S-EML based device is originated from the more and more exciton formation in the HTL with increasing current density.

The exciton confinement inside the CBP: $\operatorname{Ir}(\mathrm{ppy})_{3}$ layer in the D-EMLs devices ${ }^{8,11,17}$ can be understood based on the charge mobility in the consisting layers. From the time-offlight (TOF) measurement, CBP has high electron and hole mobility of $3 \times 10^{-4}$ and $2 \times 10^{-3} \mathrm{~cm}^{2} \mathrm{~V}^{-1} \mathrm{~s}^{-1}$ at the applied field of $0.5 \mathrm{MV} / \mathrm{cm}$, respectively. However, TCTA has the hole mobility of $3 \times 10^{-4} \mathrm{~cm}^{2} \mathrm{~V}^{-1} \mathrm{~s}^{-1}$ at the applied field of $0.5 \mathrm{MV} / \mathrm{cm}$ and very low electron mobility not measurable by the TOF method $\left(<10^{-8} \mathrm{~cm}^{2} \mathrm{~V}^{-1} \mathrm{~s}^{-1}\right)$. By doping $\operatorname{Ir}(\mathrm{ppy})_{3}$ in TCTA, transporting of electrons injected from the CBP: $\operatorname{Ir}(\text { ppy })_{3}$ layer through TCTA is effectively blocked in the layer. Electrons can only be transported by hopping between $\operatorname{Ir}(\text { ppy })_{3}$ dopant molecules. Therefore, the excitons can be mostly confined inside the CBP: $\operatorname{Ir}(\mathrm{ppy})_{3}$ layer to prevent them from formation in HTL.

In summary, we have demonstrated that the reduction of EL quantum efficiency with increasing current density in single EML [CBP: $\left.\operatorname{Ir}(\mathrm{ppy})_{3}\right]$ devices is related to the formation of excitons in the NPB HTL based on the analysis of EL spectra and exciton formation zone. By adopting D-EML structure, we achieved very low roll-off in the quantum efficiency with increasing current density in PhOLEDs, in which the hole transporting TCTA is used as one of the hosts. The external quantum efficiency was maintained constant up to $10000 \mathrm{~cd} / \mathrm{m}^{2}$ by adopting the D-EMLs in $\operatorname{Ir}(\mathrm{ppy})_{3}$ based PhOLEDs, resulting in a high external quantum efficiency at high luminance $\left[\eta_{\mathrm{ext}}=13.1 \%\right.$ at $10000 \mathrm{~cd} / \mathrm{m}^{2}$ $\left.\left(22 \mathrm{~mA} / \mathrm{cm}^{2}\right)\right]$ compared to the devices with S-EML $\left[\eta_{\text {ext }}\right.$ $=7.8 \%$ at $5400 \mathrm{~cd} / \mathrm{m}^{2}\left(20 \mathrm{~mA} / \mathrm{cm}^{2}\right)$ and $6.9 \%$ at $\left.10000 \mathrm{~cd} / \mathrm{m}^{2}\left(40 \mathrm{~mA} / \mathrm{cm}^{2}\right)\right]$. These results clearly indicate that phosphorescent OLEDs with less roll-off of efficiency at high current density can be realized by confining recombination zone inside the emitting layer and minimizing the exciton formation in hole transporting or hole blocking layers. This is a promising approach for display and solid-state lighting application.

This work was supported by the Ministry of Commerce, Industry and Energy of Korea through the OLED center, Samsung SDI, Dongwoo Finechem, and CKC Program.

${ }^{1}$ M. A. Baldo, D. F. O'Brien, Y. You, A. Shoustikov, S. Sibley, M. E. Thompson, and S. R. Forrest, Nature (London) 395, 151 (1998).

${ }^{2}$ M. A. Baldo, S. Lamansky, P. E. Burrows, M. E. Thompson, and S. R. Forrest, Appl. Phys. Lett. 75, 4 (1999).

${ }^{3}$ Y.-Y. Noh, C.-L. Lee, K. Yase, and J.-J. Kim, J. Chem. Phys. 118, 2853 (2003).

${ }^{4}$ Y.-H. Niu, M. S. Liu, J.-W. Ka, and A. K.-Y. Jen, Appl. Phys. Lett. 88, 093505 (2006).

${ }^{5}$ C. Adachi, M. A. Baldo, M. E. Thompson, and S. R. Forrest, J. Appl. Phys. 90, 5048 (2001).

${ }^{6}$ D. Tanaka, H. Sasabe, Y.-J. Li, S.-J. Su, T. Takeda, and J. Kido, Jpn. J. Appl. Phys., Part 2 46, L10 (2007).

${ }^{7}$ M. Ikai, S. Tokito, Y. Sakmoto, T. Suzuki, and Y. Taga, Appl. Phys. Lett. 79, 156 (2001).

${ }^{8}$ G. He, M. Pfeiffer, K. Leo, M. Hofmann, J. Birnstock, R. Pudzich, and J. Salbeck, Appl. Phys. Lett. 85, 3911 (2004).

${ }^{9}$ Q. Huang, K. Walzer, M. Pfeiffer, V. Lyssenko, G. He, and K. Leo, Appl. Phys. Lett. 88, 113515 (2006).

${ }^{10}$ H. J. Peng, X. L. Zhu, J. X. Sun, X. M. Yu, M. Wong, and H. S. Kwok, Appl. Phys. Lett. 88, 033509 (2006).

${ }^{11}$ T.-Y. Cho, C.-L. Lin, and C.-C. Wu, Appl. Phys. Lett. 88, 111106 (2006).

${ }^{12}$ M. A. Baldo, C. Adachi, and S. R. Forrest, Phys. Rev. B 62, 10967 (2000).

${ }^{13}$ S. Reineke, K. Walzer, and K. Leo, Phys. Rev. B 75, 125328 (2007).

${ }^{14}$ J. Kalinowski, W. Stampor, J. Mezyk, M. Cocchi, D. Virgili, V. Fattori, and P. Di Marco, Phys. Rev. B 66, 235321 (2002).

${ }^{15}$ G. He, O. Schneider, D. Qin, X. Zhou, M. Pfeiffer, and K. Leo, J. Appl. Phys. 95, 5773 (2004).

${ }^{16}$ C. Adachi, R. Kwong, and S. R. Forrest, Org. Electron. 2, 37 (2001).

${ }^{17}$ X. Zhou, D. S. Qin, M. Pfeifer, J. Blocheitz-Nimoth, A. Werner, J. Drechsel, B. Maennig, and K. Leo, Appl. Phys. Lett. 81, 4070 (2002). 